\title{
HUBUNGAN ANTARA FREKUENSI PAPARAN PORNOGRAFI DENGAN PERILAKU SEKSUAL PRANIKAH PADA REMAJA SMA/SEDERAJAT DI WILAYAH KERJA PUSKESMAS SUKAWATI I KABUPATEN GIANYAR BALI 2014
}

\author{
Muhammad Aidil Firdauz \\ Fakultas Kedokteran Universitas Udayana \\ (aidilfirdauz10@gmail.com)
}

\section{ABSTRAK}

Masalah sosial salah satunya adalah perilaku seksual pranikah semakin tinggi belakangan ini. Ini menjurus kearah tingginya angka pengidap PMS dan HIV/AIDS. Dari berbagai hasil penelitian yang dilakukan di seluruh dunia didapatkan faktor yang mengarah arah tingginya masalah perilaku seksual pranikah adalah frekuensi paparan pornografi terhadap remaja. Untuk mencari hubungan antara frekuensi paparan pornografi dengan perilaku seksual pranikah pada remaja SMA/sederajat di wilayah kerja Puskesmas Sukawati I. Jenis penelitian yang digunakan adalah penelitian secara kuantitatif dengan rancangan analitik cross sectional yang untuk mencari hubungan antara variabel bebas dan terikat, itu dimaksudkan bahwa variabel bebas dan terikat pada objek penelitian diukur dan dikumpulkan secara simultan atau pada satu waktu yang bersamaan. Metode pengambilan sampel yang dipakai dengan mengguanakan angket/kuisioner melalui metode survei yang dilakukan terhadap 136 orang siswa. Data yang terkumpul dianalisis dengan perangkat lunak komputer. Dengan analisis Chi Square. Pada penelitian ini, 19,1\% responden telah melakukan perilaku seks pranikah. Pada analisis bivariat variabel kategori frekuensi paparan $(p=0,615)$ tidak memiliki hubungan yang signifikan terhadap perilaku seks pranikah. Pada penelitian ini menggunakan nilai $p$ dibawah 0,05 . Frekuensi paparan pornografi tidak mempunyai pengaruh terhadap perilaku seksual pranikah remaja SMA/sederajat di wilayah kerja Puskesmas Sukawati I.

Kata Kunci: perilaku seksual pranikah, frekuensi paparan pornografi, faktor resiko

\begin{abstract}
One of the social problem that make big problem nowadays is premarital sexual behavior amongst teenagers. This problem can lead to many impacts such as the high incidence of HIV/AIDS and Sexual Transmited Disease. According to some research, premarital sexual behavior is influenced by pornography exposure towards teenagers. The aim of this study is to detect the relationship between frequency of pornography exposure towards the premarital sexual behavior in high school teenagers Sukawati Public Health Centre II working place. The design for this research is quantitative study with analytic cross-sectional design. To collect the sample we use questioner without the name of the respondent amongst 136 students in two high school. For analysis we use Chi Square analysis using computer software. In this study, $19,1 \%$ respondent has done a premarital sexual behavior. At bivariate analysis, frequency of pornographic exposure $(p=0,615)$ don't have a significance relationship with premarital sexual behavior. For this study, the significance is $p$ value below 0,05 . Frequency of pornographic exposure don't have a significant relationship with premarital sexual behavior.
\end{abstract}

Keyword: premarital sexual behavior, pornography exposure frequency, risk factor

\section{PENDAHULUAN}

Setiap 25 menit di Indonesia, satu orang terinfeksi HIV. 1 dari 5 orang yang baru terinfeksi HIV berumur di bawah 25 tahun. Epidemik kasus HIV disebabkan 2 penyebab terbesar yaitu transmisi melalui hubungan seksual dan injection drug user. Tanah Papua, Jakarta dan Bali merupakan propinsi yang mempunyai paling banyak kasus baru HIV per 100.000 orang.

Pada tahun 2011, 18\% kasus baru HIV mencakup kelompok umur 15-24 tahun. Umur debut seksual di Indonesia sangat muda terutama pada perempuan. Sebanyak $1 \%$ laki-laki dan $4 \%$ perempuan dilaporkan sudah berhubungan seksual sebelum 
berusia 13 tahun. Ketika sudah berusia 17 tahun, 1/3 dari remaja sekurang-kurangnya sudah sekali melakukan hubungan seksual.

Berdasarkan hasil data situasi temuan kasus HIV/AIDS menurut kabupaten di propinsi Bali, angka kumulatif kasus AIDS dan HIV dari tahun 1987 s/d April 2014. Kasus AIDS dan HIV sebanyak $7.4 \%$ berasal dari Gianyar. Dilihat dari kelompok jenis kelamin, didapatkan laki-laki lebih banyak berbanding perempuan iaitu sebanyak 65\% di kabupaten Gianyar.

Berdasarkan data yang diperoleh dari Puskesmas Sukawati I berkaitan dengan angka jumlah kehamilan dini dari bulan Januari s/d Augustus 2014. Sebanyak 16 orang telah datang dan berkonsultasi kontrol ke Puskesmas. Rata-rata usia hamil sekitar 1619 tahun. Persalinan usia dini dilaporkan sebanyak 14 kasus. Dari 14 kasus tersebut tidak satupun yang kontrol kehamilan ke Puskesmas Sukawati I. Rata-rata usia yang bersalin tersebut sekitar usia 17-19 tahun.

Salah satu program Puskesmas Sukawati I adalah PKPR (Pelayanan Kesehatan Produksi Remaja) melaporkan bahawa terdapat 2 orang yang datang berkonsultasi langsung karena mengeluhkan keluar cairan putih kehijauan dan juga gatal dan berbau. Keduanya berusia 18 tahun. Namun, masih banyak yang malu dan takut untuk berkonsultasi ke bagian PKPR dan lebih memilih untuk berkonsultasi menggunakan SMS dan menelpon pemegang program tersebut. Di dapatkan perkiraan sekitar puluhan SMS dan telpon untuk berkonsultasi akan alat kelamin mereka dan rata-rata berusia sekitar 16-19 tahun.

Beberapa faktor resiko yang didapatkan pada HIV/AIDS adalah prilaku seksual beresiko tinggi seperti tidak menggunakan kondom saat berhubungan seksual, prilaku seksual pranikah dini dan sering berganti-ganti pasangan. Penelitian ini dilakukan untuk mencari hubungan antara frekuensi paparan pornografi terhadap remaja terhadap prilaku seksual pranikah remaja SMA/sederajat di wilayah kerja puskesmas Sukawati IDi antara rumusan masalah yang didapatkan untuk menjalankan penelitian ini adalah apakah ada hubungan antara frekuensi paparan pornografi terhadap perilaku seksual pranikah pada remaja SMA/sederajat di wilayah kerja Puskesmas Sukawati I? Antara tujuan penelitian adalah untuk mengetahui faktor yang mempengaruhi perilaku seks pranikah pada remaja SMA/sederajat di wilayah kerja Puskesmas Sukawati I, mengetahui karakteristik demografi remaja di wilayah kerja Puskesmas Sukawati I, mengetahui gambaran prilaku seksual pranikah remaja di wilayah kerja Puskesmas Sukawati I, mengetahui gambaran frekuensi paparan pornografi pada remaja SMA/sederajat di wilayah kerja Puskesmas Sukawati I, dan menganalisis hubungan antara frekuensi paparan pornografi dengan prilaku seksual pranikah pada remaja SMA/sederajat di wilayah kerja Puskesmas Sukawati I.

Manfaat peneneitian yang dijalankan bagi remaja adalah dengan didapatkan hasil penelitian ini diharapkan dapat memberikan gambaran tentang faktor yang mempengaruhi perilaku seksual pranikah pada remaja SMA/sederajat di Sukawati. Bagi Instansi Kesehatan diharapkan dapat bermanfaat bagi Dinas Kesehatan, dan instansi terkait untuk perbaikan perencanaan maupun implementasi program kesehatan reproduksi. Bagi peneliti dapat mengembangkan wawasan peneliti dan pengalaman berharga dalam melatih kemampuan peneliti dalam melakukan penelitian yang berkaitan dengan faktor yang mempengaruhi perilaku seksual pranikah pada remaja SMA/sederajat di Sukawati. Bagi peneliti lain sebagai data dasar untuk penelitian selanjutnya.

\section{Perilaku seks pra nikah}

Perilaku seks pra nikah adalah tingkah laku yang didorong oleh hasrat seksual baik yang dilakukan oleh diri sendiri, lawan jenis, maupun sesama jenis tanpa adanya ikatan pernikahan menurut agama (Sarwono, 2003). Remaja melakukan berbagai macam perilaku seksual beresiko yang terdiri atas tahapantahapan tertentu yaitu dimulai dari berpegangan tangan, cium kering, cium basah, berpelukan, memegang atau meraba bagian sensitif, petting, oral sex, dan bersenggama (sexual intercourse) (Irawati,2002).

Perilaku seksual pada remaja dapat diwujudkan dalam tingkah laku yang bermacammacam, mulai dari perasaan tertarik, berkencan, berpegangan tangan, mencium pipi, berpelukan, mencium bibir, memegang buah dada di atas baju, memegang buah dada di balik baju, memegang alat kelamin di atas baju, memegang alat kelamin di bawah baju, dan melakukan senggama (Sarwono, 2003).

Beberapa studi melaporkan bahwa dampak buruk dari seks pranikah ada banyak, diantaranya kehamilan usia dini dan penyakit menular seksual. Adolesen cenderung mempunyai pasangan seksual yang lima atau enam tahun lebih tua dan mempunyai pasangan lebih dari satu. Beberapa studi di ethiopia menunjukkan bahwa banyak faktor yang mempengaruhi debut seksual pra nikah (Ojira, et al., 2012).

Jenis kelamin dan kebiasaan nonton tayangan porno dapat meningkatkan kecenderungan untuk melakukan hubungan seksual. Merokok, mengonsumsi alkohol, sedang atau pernah berpacaran meningkatkan kecenderungan untuk melakukan hubungan seks pra nikah. Sedangkan, tinggal di rumah bersama orangtua 
dapat menurunkan risiko untuk melakukan hubungan seks pra nikah (Ojira, et al., 2012).

\section{Pornografi}

Pornografi dalam bahasa Yunani disebut pornographia adalah penggambaran tubih manusia atau perilaku seksual manusia secara terbuka (eksplisit) dengan tujuan membangkitkan birahi (gairah seksual). Pornografi dapat menggunakan berbagai media, teks tertulis maupun lisan, fotofoto, ukiran, gambar, gambar bergerak (termasuk animasi), dan suara seperti misalnya suara orang yang bernapas tersengal-sengal.

Pornografi dapat menunjukkan gambaran telanjang seperti gambar payudara maupun kelamin wanita dan dalam keadaan yang merangsang. Pornografi juga sering menggambarkan aktifitas seksual pada pria dan wanita, seperti coitus, hubungan seks per anal, fellatio, cunnilingus dan seks yang melibatkan banyak pasangan. Gambaran ejakulasi pada pria dan wanita juga digambarkan dalam pornografi (Malti-Douglas, 2007)

Beberapa penelitian mengungkapkan bahwa laki-laki lebih banyak menjadi konsumen berbagai jenis pornografi daripada wanita. Pornografi juga dapat memicu laki-laki melakukan masturbasi. Pria juga lebih sering tertarik terhadap pornografi dan melakukannya secara rutin. Beberapa penelitian dilakukan untuk mencari hubungan pornografi terhadap hubungan jangka panjang, feminist dan kekerasan terhadap wanita (Malamuth et al., 2007).

Gender merupakan prediktor yang penting tentang kepercayaan terhadap pornografi. Perempuan mempunyai lebih banyak tanggapan negatif terhadap material seksual. Beberapa studi menunjukkan bahwa wanita menganggap pornografi dapat memicu terjadinya pemerkosaan dan penurunan moral.

Umur dan tingkat pendidikan juga berpengaruh terhadap tanggapan terhadap pornografi. Individu yang umurnya lebih tua cenderung menganggap pornografi mempunyai banyak efek negatif. Sedangkan orang yang tingkat pendidikannya lebih tinggi mempunyai toleransi yang lebih tinggi terhadap pornografi (Parillo et al., 2008).

Menurut survey yang dilakukan oleh (McKee, 2007) pornografi dapat member dampak positif terhadap orang seperti menurunnya pengekangan terhadap seks, lebih terbuka terhadap seks, lebih toleran terhadap aktivitas orang lain, lebih bisa memuaskan pasangan dalam berhubungan seks, dan menjadikan seks sebagai topik yang didiskusikan bersama suami atau istri.

Adapun beberapa dampak buruk dari pornografi adalah meningkatnya perilaku negatif terhadap wanita, menurunnya empati terhadap korban kekerasan seksual dan meningkatnya perilaku memaksa pada seksual. Terjadinya peningkatan perilaku negatif terhadap wanita terjadi karena media porno yang menggunakan wanita sebagai alat untuk memuaskan kebutuhan seks pria (McKee, 2007).

\section{Metode}

Jenis penelitian yang digunakan adalah penelitian secara kuantitatif dengan rancangan analitik cross sectional yang untuk mencari hubungan antara variabel bebas dan terikat, itu dimaksudkan bahwa variabel bebas dan terikat pada objek penelitian diukur dan dikumpulkan secara simultan atau pada satu waktu yang bersamaan.

Metode pendekatan yang dipakai dengan mengguanakan angket/kuisioner melalui metode survei yaitu metode penelitian yang dilakukan terhadap sekumpulan obyek, biasanya cukup banyak, tapi hanya mengambil sebagian dari populasi tersebut dalam jangka waktu tertentu.

Variabel-variabel dalam penelitian ini adalah variabel Independent (bebas) dalam penelitian ini adalah frekuensi paparan pornografi. Variabel Dependent (terikat) adalah perilaku seks pranikah pada remaja. Variabel pengganggu atau confounding variabel pada penelitian ini adalah faktor-faktor yang kemungkinan berhubungan dengan perilaku seksual pranikah.

Variabel pengganggu pada penelitian ini dikontrol dengan pemilihan siswa SMA di wilayah kerja puskesmas sukawati 1 dan pada kriteria inklusi dari penelitian, yang terdiri daripada tingkat pengetahuan, umur, dan jenis kelamin.

Variabel rambang adalah variabel yang pengaruhnya diabaikan, meliputi sikap, pengendalian diri, rasa percaya diri, aktivitas sosial, gaya hidup, sosial budaya, dan nilai dan norma.

Penelitian ini dilaksanakan pada bulan September 2014 sedangkan pengambilan data dilaksanakan pada tanggal 30 September 2014 dan 1 Oktober 2014 dan tempat penelitian ini dilakukan pada Sekolah Menengah Atas/Sederajat di Kecamatan Sukawati.

Populasi dalam penelitian ini adalah seluruh siswa Sekolah Menengah Atas/Sederajat negeri maupun swasta di kecamatan Sukawati, yaitu siswa SMK Saraswati Sukawati berjumlah 92 orang dan SMAN 1 Sukawati berjumlah 1043 orang, jumlah total populasi sebanyak 1135 siswa. Besar sampel pada penelitian ini dihitung berdasarkan besar sampel untuk uji hipotesis terhadap 2 proporsi independen, maka untuk menetapkan jumlah sampel dapat menggunakan rumus yang yaitu:

$$
\mathrm{n} 1=\mathrm{n} 2=\frac{(\mathrm{z} \alpha \sqrt{2 \mathrm{PQ}}+\mathrm{z} \beta \sqrt{\mathrm{P} 1 \mathrm{Q} 1+\mathrm{P} 2 \mathrm{Q} 2})^{2}}{(\mathrm{P} 1-\mathrm{P} 2)^{2}}
$$

Keterangan:

$\mathrm{P}_{1}=$ proporsi efek standar (dari pustaka)

$\mathrm{P}_{2}=$ proporsi efek yang diteliti (clinical judgement)

$\alpha=$ tingkat kemaknaan (ditetapkan peneliti)

$Z_{\beta}=$ power (ditetapkan peneliti) 
Penghitungan jumlah sampel adalah sebagai berikut:

$z_{\alpha}=1,96 ; z_{\beta}=0,842 ; P_{1}=0,3 ; P=1 / 2 \times(0,3+0,1)=0,2$

$\mathrm{n}_{1}=\mathrm{n}_{2}=\frac{(1,96 \sqrt{2(0,2)(0,8)}+0,842 \sqrt{(0,3 \times 0,7)+(0,1 \mathrm{X} 0,9)})^{2}}{(0,3-0,1)^{2}}$
$\mathrm{n}_{1}=\mathrm{n}_{2}=62$

Jadi jumlah sampel minimal pada penelitian ini sebanyak 124 siswa. Dalam penelitian ini teknik pengambilan sampel dilakukan dengan dua tahap. Dilihat dari jumlah total siswa masing-masing SMA/sederajat terdapat perbedaan yang sangat signifikan, maka tahap pertama pengambilan sampel dilakukan secara proportional to size, dimaksudkan jumlah sampel akan diambil sesuai dengan jumlah total siswa pada sekolah tersebut dibandingkan dengan jumlah total populasi dan disesuaikan dengan besar sampel yang sudah ditentukan.

$$
\frac{\text { populasi }}{\text { total populasi }} \times \text { total sampel }
$$

Maka jumlah sampel yang diambil masing-masing sekolah yaitu;

1. SMK Saraswati Sukawati

$$
\frac{92}{1135} \times 124=10
$$

Jadi sampel minimal yang diambil dari SMK Saraswati Sukawati adalah sebanyak 10 siswa.

2. SMA Negeri 1 Sukawati

$\frac{1043}{1135} \times 124=114$

Jadi sampel minimal yang diambil dari SMA Negeri 1

Sukawati adalah sebanyak 114 siswa.

Setelah didapatkan proporsi sampel masingmasing sekolah maka dilakukan tahap kedua yaitu dengan teknik pengambilan sampel acak kelompok (cluster random sampling) dengan kelas di masingmasing sekolah sebagai klasternya, yaitu untuk SMK Saraswati Sukawati diambil kelas XII sebagai clusternya, dengan jumlah siswa 11 siswa dan untuk SMA Negeri 1 Sukawati diambil kelas X MIPA 2 dengan jumlah 42 siswa, XI IPS 1 sejumlah 44 siswa dan XII IPB sejumlah 39 siswa.

Jadi total sampel pada penelitian ini adalah 136 sampel. Sampel pada penelitian ini adalah siswa Sekolah Menengah Atas/Sederajat negeri maupun swasta di kecamatan Sukawati dengan criteria Kriteria Inklusi: Siswa SMA/Sederajat yang bersedia menjadi responden dan yang belum menikah manakala untuk kriteria ekslusi adalah siswa yang tidak bisa mengisi kuisioner karena sakit dan yang sudah menikah.

Alat penelitian yang digunakan dalam pengumpulan data untuk tiap variabel menggunakan angket/kuisioner. Cara pengumpulan data yaitu dengan menyebar kuisioner yang telah disediakan dengan pertanyaan yang dijawab oleh responden. Instrumen kuisioner dipilih karena kuisioner adalah salah satu media penghubung antara peneliti dan responden serta dapat memperoleh data yang benar-benar, diperlukan peneliti, juga dapat menghemat waktu, biaya dan tenaga.

Kuisioner berisi paparan pornografi yang teridri 15 pertanyaan dalam bentuk pilihan tidak pernah, kadangkadang, sering untuk mengetahui frekuensi paparan. Untuk jawaban tidak pernah=0, kadang-kadang=1, dan sering=2 dan perilaku seksual pranikah siswa yang terdiri dari 5 pertanyaan dalam bentuk pilihan iya dan tidak, pernah, tidak pernah dan ragu-ragu, dan pilihan ganda (jawaban boleh lebih dari satu).

Jenis data yang dikumpulkan terdiri dari data primer dan data sekunder. Data primer meliputi frekuensi paparan pornografi, status sosioekonomi dan psikososial serta seks pranikah, kesemua data tersebut diatas diperoleh dari hasil pengisian kuisioner. Sedang data sekunder yaitu data penunjang dari data primer. Data primer adalah data yang didapatkan dari hasil pengisian kuisioner yang dilakukan oleh peneliti terhadap responden.

Data sekunder adalah pendukung data primer yang meliputi data demografis dan sumbernya adalah daripada data dinas kesehatan kabupaten Gianyar, Data PKPR puskesmas Sukawati 1, Data mengenai prevalensi kejadian HIV dan IMS, Profil beberapa SMA/sederajat tempat pengambilan data, laporan hasil penelitian, jurnal, buku dan artikel.

\section{Hasil Penelitian \\ Karakteristik koresponden}

Dari 136 responden yang telah memenuhi syarat untuk diteliti, laki-laki berjumlah 80 orang $(58,8 \%)$ sedangkan perempuan berjumlah 56 orang (41,2\%). Dari agama responden, 97,8\% adalah Hindu sedangkan Islam, Budha, Katolik dan Protestan masingmasing 0,7\%. Dari suku responden 99,3\% diantaranya suku Bali dan 0,7\% diantaranya suku Jawa. 47,8\% responden adalah anak pertama, 31,6\% adalah anak kedua, 13,2\% adalah anak ketiga, 6,6\% adalah anak keempat dan $0,7 \%$ adalah anak kelima. Umur responden adalah 15 tahu, 16 tahun, 17 tahun, 18 tahun, 19 tahun dan 21 tahun.

Tabel 1 Karakteristik Responden Penelitian berdasarkan Jenis Kelamin

Jenis Kelamin $\quad$ Frekuensi $\quad$ Persentase (\%)

\begin{tabular}{lcc}
\hline Laki-laki & 80 & 58,8 \\
Perempuan & 56 & 41,2 \\
Total & 136 & 100 \\
\hline
\end{tabular}


Tabel 2 Karakteristik Responden Penelitian berdasarkan Umur

\begin{tabular}{lll}
\hline Umur (Tahun) & Frekuensi & Persentase (\%) \\
\hline 15 & 5 & 3,7 \\
16 & 60 & 41,1 \\
17 & 65 & 47,8 \\
18 & 4 & 2,9 \\
19 & 1 & 0,7 \\
21 & 1 & 0,7 \\
Total & 136 & 100 \\
\hline
\end{tabular}

Tabel 3 Karakteristik Responden Penelitian berdasarkan Suku

\begin{tabular}{lll}
\hline Suku & Frekuensi & Persentase (\%) \\
\hline Bali & 135 & 99,3 \\
Jawa & 1 & 0,7 \\
\hline Total & 136 & 100 \\
& & \\
\hline
\end{tabular}

Tabel 4 Karakteristik Responden Penelitian berdasarkan Agama

\begin{tabular}{lll}
\hline Agama & Frekuensi & Persentase (\%) \\
\hline Hindu & 133 & 97,8 \\
Islam & 1 & 0,7 \\
Katolik & 1 & 0,7 \\
Protestan & 1 & 0,7 \\
\hline Total & 136 & 0,7 \\
\hline
\end{tabular}

\section{Gambaran Perilaku Seksual Pranikah Responden}

Dari seluruh responden, $19,1 \%$ responden telah melakukan perilaku seks pra-nikah. Yang dimaksud dalam perilaku seks pranikah adalah oral sex dan/atau berhubungan kelamin (sexual intercourse). Sedangkan perilaku seksual yang paling banyak dilakukan adalah berciuman bibir (kissing) sebanyak $66,9 \%$. Perilaku seksual yang paling sering dilakukan oleh responden adalah kissing sebanyak 58,1\%. Adapun alasan yang paling sering untuk melakukan perilaku seksual adalah iseng sebanyak $36,8 \%$ disusul ingin mencoba hal baru sebanyak 29,4\%. Dari Seluruh responden, $87,5 \%$ pernah pacaran sedangkan $12,5 \%$ belum pernah pacaran. Untuk ketertarikan terhadap jenis kelamin, 98,5\% heteroseksual dan 1,5\% biseksual.

Tabel 5 Perilaku Seksual Pranikah pada Responden

\begin{tabular}{llc}
\hline $\begin{array}{l}\text { Perilaku } \\
\text { Seksual } \\
\text { Pranikah }\end{array}$ & Frekuensi & Persentase (\%) \\
\hline Ya & 26 & 19,1 \\
Tidak & 110 & 80,9 \\
Total & 136 & 100 \\
\hline
\end{tabular}

Tabel 6 Gambaran Perilaku Seksual pada Responden Penelitian

\begin{tabular}{lllll}
\hline $\begin{array}{l}\text { Perilaku } \\
\text { Seksual }\end{array}$ & $\begin{array}{l}\text { Pernah } \\
\text { (\%) }\end{array}$ & $\begin{array}{l}\text { Tidak } \\
\text { Pernah } \\
(\%)\end{array}$ & $\begin{array}{l}\text { Ragu- } \\
\text { ragu } \\
(\%)\end{array}$ & $\begin{array}{l}\text { Total } \\
(\%)\end{array}$ \\
\hline Kissing & 66,9 & 29,4 & 3,7 & 100 \\
Necking & 25,7 & 66,9 & 7,4 & 100 \\
Meraba & 31 & 69,9 & 22,8 & 100 \\
Petting & 14,0 & 83,1 & 2,9 & 100 \\
Oral & 5,9 & 89,7 & 4,4 & 100 \\
Intercourse & 14,7 & 81,6 & 3,7 & 100 \\
\hline
\end{tabular}

Tabel 7 Gambaran Perilaku Seksual Paling Sering pada Responden Penelitian

\begin{tabular}{|c|c|c|}
\hline $\begin{array}{l}\text { Perilaku } \\
\text { Seksual Paling } \\
\text { Sering }\end{array}$ & Frekuensi & Persentase (\%) \\
\hline Tidak Pernah & 43 & 31,6 \\
\hline Kissing & 79 & 58,1 \\
\hline Necking & 5 & 3,7 \\
\hline Meraba & 4 & 2,9 \\
\hline Petting & 1 & 0,7 \\
\hline Oral & 0 & 0 \\
\hline Intercourse & 4 & 2,9 \\
\hline Total & 136 & 100 \\
\hline
\end{tabular}

Tabel 8 Gambaran Alasan Responden Melakukan Perilaku Seksual

\begin{tabular}{llll}
\hline $\begin{array}{l}\text { Alasan } \\
\text { melakukan } \\
\text { Perilaku Seksual }\end{array}$ & Iya (\%) & $\begin{array}{l}\text { Tidak } \\
\text { (\%) }\end{array}$ & Total (\%) \\
\hline Dipaksa Pacar & 11,8 & 88,2 & 100 \\
\hline $\begin{array}{l}\text { Ingin Mencoba } \\
\text { Mempraktekan }\end{array}$ & 5,1 & 94,9 & 100 \\
$\begin{array}{l}\text { Mang Dilihat di } \\
\text { Media Pornografi }\end{array}$ & 0,7 & 99,3 & 100 \\
$\begin{array}{l}\text { Masalah Ekonomi } \\
\text { Cari Perhatian }\end{array}$ & 0 & 100 & 100 \\
\begin{tabular}{l} 
Orang Tua \\
\hline
\end{tabular} & & & \\
\hline
\end{tabular}




\begin{tabular}{llll}
\hline Iseng & 36,8 & 63,2 & 100 \\
\hline
\end{tabular}

\section{Gambaran Paparan Pornografi pada Responden}

Dalam penelitian ini, 96,8\% responden telah terpapar pornografi sedangkan sedangkan 3,2 \% belum pernah terpapar pornografi. Dalam analisis multivaiat dan univariat, kategori paparan pornografi dibagi menjadi jarang dan sering. Dari 13 media yang kami tetapkan, tidak pernah bernilai 0 . Jarang bernilai 1 dan sering bernilai 2. Untuk terakhir terpapar, kita beri nilai 0 untuk lebih dari 1 bulan yang lalu, 1 untuk kurang dari 1 bulan yang lalu dan 2 untuk kurang dari 1 minggu yang lalu.

Setelah mendapat skor tersebut, kami merataratakan skor tersebut. Skor terendah adalah 0 dan skor tertinggi adalah 22 dan skor rata-rata adalah 7,21. Jika dibawah rata-rata kita sebut "jarang terpapar" dan skor rata-rata keatas kita sebut "sering terpapar"

Tabel 9 Gambaran Kategori Paparan Pornografi pada Responden Penelitian

\begin{tabular}{lll}
\hline $\begin{array}{l}\text { Kategori } \\
\text { Paparan }\end{array}$ & Frekuensi & Persentase (\%) \\
\hline Jarang & 80 & 58,8 \\
Sering & 56 & 41,2 \\
\hline Total & 124 & 100 \\
\hline
\end{tabular}

\section{Analisis Faktor-Faktor yang Berpengaruh terhadap Perilaku Seks Pranikah}

Analisis bivariat dengan uji chi-square digunakan untuk mengetahui hubungan faktor risiko frekuensi paparan pornografi terhadap hubungan seks pranikah. Hasil tabulasi silang hubungan antara frekuensi paparan pornografi terhadap hubungan seks pranikah dapat dilihat pada tabel 10.

Tabel 10 Hubungan Kategori Frekuensi Paparan Pornografi pada Perilaku Seks Pranikah

\begin{tabular}{|c|c|c|c|}
\hline Kategori & Perilaku & Seks & Total \\
\hline Frekuensi & Pranikah & & \\
\hline Paparan & Iya & Tidak & \\
\hline Sering & 12 & 44 & 74 \\
\hline
\end{tabular}

\begin{tabular}{lllll} 
Jarang & 14 & 64 & 50 & \\
& $17,9 \%$ & $82,1 \%$ & $100 \%$ & \\
& & & & \\
\hline $\mathrm{PR}=1,194$ & $95 \% \mathrm{IK}=0,599-2,381$ & $\mathrm{X}^{2}=0,252 \mathrm{df}=1$ & $\mathrm{p}=$ \\
0,615 & & & &
\end{tabular}

\section{Pembahasan \\ Karakteristik Responden}

Prevalensi perilaku seksual pranikah pada penelitian ini didapatkan sebesar 19,1\%. Hasil ini lebih rendah dari penelitian yang dilakukan oleh Biney tahun 2012 yang mendapatkan prevalensi perilaku seksual pranikah di daerah urban Accra, Ghana sebesar 30,21\% (Biney et.al, 2012). Namun hasil ini lebih rendah dibandingkan dengan penelitian Agung tahun 2013 pada remaja SMAN 2 Surakarta yang mendapatkan prevalensi perilaku seksual pranikah di Indonesia sebesar 20,39\% (Agung, 2013).

Prevalensi perilaku seksual pranikah juga didapatkan jauh lebih tinggi pada kelompok laki-laki dibandingkan wanita. Laki-laki $26,3 \%$ sedangkan wanita $8,9 \%$. Hal ini sejalan dengan penelitian yang dilakukan di Semarang yang mendapatkan prevalensi perilaku seksual pranikah lebih tinggi pada laki-laki (Wahyuni, 2009). Hal ini kemungkinan disebabkan karena kelompok laki-laki pada penelitian ini kebanyakan mendapat banyak informasi negatif yang menimbulkan persepsi yang negatif terhdapat suatu hal.

Umur responden dengan perilaku seksual pranikah pada penelitian ini didapatkan rata-rata lebih tinggi dibandingkan responden tanpa perilaku seksual pranikah. Hal ini kemungkinan disebabkan karena dengan meningkatnya umur maka kemungkinan akibat pubertas dan peningkatan hormon seksual.

\section{Hubungan antara Frekuensi Paparan Pornografi dengan Prilaku Seksual Pranikah}

Pada analisis bivariat, didapatkan hasil bahwa 21,4\% pada kelompok frekuensi sering terpapar pornografi dan 17,9\% kelompok frekuensi sering terpapar pornografi sudah melakukan perilaku seks pranikah. Menurut Michael dan Clive (2003), frekuensi paparan pornografi dibagi kepada 2 iaitu jarang terpapar dan sering terpapar pornografi. Dalam penelitian ini, frekuensi paparan pornografi ditentukan oleh indikator pernah menonton atau tidak, sumber pornografi dan seberapa sering terpapar dan kapan terakhir kali terpapar sumber pornografi.

Hasil analisis Chi Square antara faktor frekuensi paparan pornografi dengan perilaku seksual pranikah didapatkan nilai PR $=1,194$. Ini berarti sering terpapar pornografi merupakan faktor risiko terhadap perilaku seks pranikah. Pada nilai 95\% confidence interval pada hubungan frekuensi paparan pornografi dengan perilaku seksual pranikah adalah 0,599-2,381. Rentang confidence interval melewati angka 1 ini membawa arti tidak signifikan.

Pada penelitian Adriana Biney et al (2012) didapatkan nilai OR pada kelompok sering terpapar pornografi lebih besar bernilai 9,81 dengan 95\% confidence interval 3.11-30,91. Penilitian Adriana Biney et al (2012) mempunyai OR yang lebih besar dan bernilai signifikan. Pada penelitian, nilai $\mathrm{p}$ untuk hubungan frekuensi paparan pornografi terhadap perilaku seksual pranikah adalah 0,615 yang membawa arti tiada hubungan signifikan antara hubungan frekuensi paparan pornografi dengan perilaku seksual 
pranikah. Nilai signifikan akan diperoleh jika nilai $p<0,05$.

Peneliti memperkirakan beberapa faktor yang menjurus ke arah hasil yang tidak mempunyai hubungan antara frekuensi paparan pornografi terhadap perilaku seksual pranikah. Yang pertama adalah dari aspek kesensitifan variable yaitu pernah berhubungan seksual. Di sini meskipun mendapat banyak laporan dari program kesehatan remaja daripada puskesmas namun hasil kuesioner menunjukkan hanya sebagian kecil yang mengaku bahwa pernah berhubungan seksual iaitu oral seks dan intercourse. Ini dicurigai karena para siswa yang menjawab mungkin merasa takut akan bocornya informasi ke pihak berwajib dan ditangkap.

Dalam menjawab kuesioner dilakukan di dalam kelas dan para siswa duduk bersampingan antara satu sama yang lain. Ini memungkinkan untuk tidak menjadi jujur dalam menjawab kuesioner karena takut diketahui oleh teman. Ini berpenganaruh dalam menjawab kuesioner. Di samping itu, didapati beberapa siswa tidak berlaku secara terang-terangan karena menyontek jawaban teman karena malas untuk mengambil waktu dan menjawab.

Kredibilitas respponden juga bermasalah dalam penelitian ini. Diketahui bahwa responden terdiri daripada kelompok siswa SMA yang rata-rata berumur 16-18 tahun. Karena banyaknya faktor eksternal seperti takut diketahui oleh teman menyebabkan sesetengah responden menjawab dengan mencari aman iaitu dengan tidak mengakui hal sebenarnya. Ini dicurigai adanya kasus yang tidak terlaporkan yang akhirnya menyebabkan hasil penelitian tidak mempunyai hubungan antara frekuensi paparan pornografi dengan perilaku seksual pranikah.

\section{Keterbatasan Penelitian}

Keterbatasan dalam penelitian ini adalah adanya kemungkinan recall bias saat menjawab pertanyaan mengenai kapan pertama kali terpapar pornografi dan pertanyaan mengenai penghasilan orang tua. Juga karena tidak semua responden menjawab jujur dan sungguh-sungguh sesuai apa yang dialami dengan pertanyaan-pertanyaan yang ada pada kuisioner. Hal ini kemungkinan terjadi karena responden merasa khawatir dengan kerahasiaan jawabannya.

Upaya yang dilakukan adalah dengan tidak mencantumkan identitas (nama) dalam lembar kuisioner dan yang kedua adalah karena Peneliti belum menemukan standar baku kuisioner dan sistem skoring saat pengolahan data (measurement bias) sehingga hanya berdasarkan pemahaman dan pengalaman dari peneliti sendiri.

\section{Simpulan}

Dari hasil penelitian ini dapat ditarik simpulan, yaitu dari 136 responden 19,1 \% diantaranya telah melakukan perilaku seks pranikah. Dari seluruh responden laki-laki, 26,3\% telah melakukan perilaku seks pranikah. Sedangkan dari seluruh responden perrempuan $8,9 \%$ telah melakukan perilaku seks pranikah.

Frekuensi paparan pornografi tidak berpengaruh signifikan terhadap perilaku seks pranikah $(p=0,615)$. Nilai $P R=1,194$ dan $95 \% \mathrm{Cl}=0,599-2,581$. Ini berarti frekuensi paparan pornografi sering sebagai faktor risiko namun tidak signifikan.

\section{Saran}

Saran yang dapat diberikan dari penelitian ini, seperti menguji variabel rambang lainnya terhadap perilaku seksual pranikah pada remaja SMA/sederajat di wilayah kerja Puskesmas Sukawati IPuskesmas Sukawati I lebih giat melakukan sosialisasi bahaya seks pranikah karena prevalensi seks pranikah $21,0 \%$ pada remaja SMA/sederajat di wilayah kerja Puskesmas Sukawati I

\section{DAFTAR PUSTAKA}

1. Adler, Nancy E., Katherine Newman. Socioeconomic Disparities In Health: Pathways And Policies. Health Affairs, 21, no.2 (2002):60-76

2. Chiao, Chi., Chin-Chun Yi dan Kate Ksobiech. Exploring the relationship between premarital sex and cigarette/alcohol use among college students in Taiwan: a cohort study. BMC Public Health 2012, 12:527

3. House, James S., Landis, Karl L., Umberson, Debra., Social Relationship and Health. Science. 2003. 241. $4865: 540-545$

4. Hyoscyamina, Darosy Endah. Peran Keluarga Dalam Membangun Karakter Anak. Jurnal Psikologi Undip 10 (2) 2011 : 144-152

5. Irawati dan Prihyugiarto, I. 2005. FaktorFaktor Yang Mempengaruhi Sikap Terhadap Perilaku Seksual Pria Nikah Pada Remaja Di Indonesia: BKKBN.

6. Malamuth, Neil ., Ed. Roy F. Baumeister., Kathleen D. Vohs. 2007 Pornography. Encyclopedia of Social Psychology. Sage. California. 678-680

7. Malti-Douglas, Fedwa., Roof, Judith. 2007. Pornohraphy. Encyclopedia of Sex and Gender. MacMillan : Detroit. Pp 1173-1179

8. McKee, Alan (2007) Positive and negative effects of pornography as attributed by consumers. Australian Journal of Communication 34(1):pp. 87-104.

9. Ojira, Lemessa., Yemane Berhane dan Alemayehu Worku. Pre-marital sexual debut and its associated factors among in-school 
adolescents in eastern Ethiopia. BMC Public Health 2012, 12:375

10. Parillo, Vincent N, Suarez, Alice E., 2008. Pornography. Encyclopedia of Social Problems. SAGE : California. 687-690
11. Salkind, Ed Neil J., Kristin Ramussen. 2008. Psychosocial Development. Encyclopedia of Psychology. SAGE Publication : California. 819825

12. Sarwono W.S. 2003. Psikologi Remaja. Jakarta: Grafindo Persada. 